\title{
PP2A activity is controlled by methylation and regulates oncoprotein expression in melanoma cells: A mechanism which participates in growth inhibition induced by chloroethylnitrosourea treatment
}

\author{
SAMUEL GUÉNIN ${ }^{1}$, LAURENT SCHWARTZ ${ }^{2}$, DANIEL MORVAN ${ }^{1-3}$, JEAN MARC STEYAERT $^{4}$, \\ AMANDINE POIGNET $^{1}$, JEAN CLAUDE MADELMONT ${ }^{1}$ and AICHA DEMIDEM ${ }^{1}$ \\ ${ }^{1}$ UMR INSERM 484, 63005 Cedex Clermont-Ferrand; ${ }^{2}$ Service de Radiothérapie, Hôpital de la Pitié Salpetrière, Paris 75013; \\ ${ }^{3}$ CLCC d'Auvergne, 63005 Clermont-Ferrand; ${ }^{4}$ Ecole Polytechnique, Laboratoire d'informatique, Palaiseau 91128, France
}

Received April 26, 2007; Accepted July 2, 2007

\begin{abstract}
Protein phosphatase 2A (PP2A), an Akt pathway inhibitor, is considered to be activated by methylation of its catalytic subunit. Also PP2A downregulation was proposed to take part in carcinogenesis. Recently, PP2A activation was shown to be activated in response to DNA damage. To obtain further information on the role of PP2A in tumors and response to DNA damage, we investigated the relationship between PP2A methylation and activity, cell proliferation, Akt activation, c-Myc expression and PTEN activity in B16 melanoma cells untreated and after chloroethylnitrosourea (CENU) treatment. In untreated cells, okadaic acid, an antagonist of PP2A methylation, inhibited PP2A activity, stimulated cell proliferation, increased Akt activation and c-Myc expression. Xylulose-5-phosphate, an agonist of PP2A methylation, increased PP2A activity, decreased cell proliferation, Akt activation and c-Myc expression. However, both PP2A methylation modulators increased PTEN activity. During the response to CENU treatment, PP2A methylation and activity were strongly increased, Akt activation and c-Myc expression were decreased. However PTEN activity was increased. After tumor cell growth recovery, these modifications were moderately decreased. PP2A methylation was quantified and correlated positively with PP2A activity, and negatively with criteria for cell aggressiveness (cell proliferation, Akt activation, c-Myc expression). Based on these data, PP2A methylation status controls PP2A activity and oncoproteins expression and PP2A is strongly activated after CENU treatment thus partly explaining the growth inhibition in response to this agent. It follows that PP2A
\end{abstract}

Correspondence to: Dr Aïcha Demidem, INSERM UMR 484, Rue Montalembert, BP 84, Clermont Ferrand Cedex 63005, France E-mail: demidem@inserm484.u-clermont1.fr

Key words: PP2A, transmethylation, chloroethylnitrosourea, DNA damage, oncoproteins, tumor cell aggressiveness promethylating agents are potential candidates for anticancer drugs.

\section{Introduction}

Among the major cellular proteins, protein phosphatase $2 \mathrm{~A}$ (PP2A) is the most common phosphatase accounting for about $0.05-0.1 \%$ of the total cell protein content (1). PP2A is one of the major regulatory protein of the Akt/PKB pathway. PP2A inactivates Akt by dephosphorylation $(1,2)$. PP2A has a regulatory role in the Akt/PKB pathway together with phosphatase and tensin homolog deleted on chromosome 10 (PTEN, also known as MMAC1). The Akt/PKB pathway is implicated in cell proliferation, protein synthesis, resistance to apoptosis and is often mutated in cancer (2-4). PP2A activity was shown to be dramatically decreased in tumor cells suggesting that PP2A dysfunction might contribute to cell transformation $(5,6)$. Recently PP2A was shown to be activated in response to DNA damage thus inhibiting pololike kinase 1 and inducing mitosis blockade (7). The response to DNA damage may also involve the Akt pathway through the inhibition of p53 leading to the transcriptional regulation of a variety of genes involved in cell cycle control and cell survival (8-10).

We previously reported that B 16 melanoma cells responded to chloroethylnitrosourea (CENU)-induced DNA damage (11), by $\mathrm{G}_{2} / \mathrm{M}$ cell cycle arrest, biopolar spindle blockade, glycolysis downregulation followed by adaptative and/or redifferentiation processes $(12,13)$. This suggested the inhibition of the Akt/PKB pathway as a possible consequence of PP2A activation in response to DNA damage.

PP2A activity is regulated by posttranslational modification by phosphorylation or methylation (14). Phosphorylation on $\mathrm{Tyr}^{204}$ and $\mathrm{Tyr}^{307}$ of the $\mathrm{C}$ subunit can inhibit PP2A activity (1). However, PP2A activity mainly depends on methylation (1). PP2A is a trimeric serine/threonine phosphatase: the regulatory subunit $\mathrm{B}$, is recruited by a $\mathrm{C}$-A dimer composed of the catalytic subunit $\mathrm{C}$ (PP2AC), and the structural subunit A. The recruitment takes place when $\mathrm{C}$ gets carboxyl-methylated 
on the terminal $\mathrm{Leu}^{309}$ and results in the assembling of the active PP2A trimer $(1,5,15)$. PP2A methylation is considered to result from the opposing activities of a specific S-adenosylL-methionine (SAM)-dependent leucine carboxymethyltransferase and a specific carboxyl methylesterase, the regulation of which is not fully understood $(16,17)$. Furthermore, there are conflicting reports on the relationship between PP2A methylation and activity (1).

The goal of this article was to get deeper knowledge on the role of PP2A in tumors and in response to DNA damage. We investigated the relationship between PP2A methylation, activity and function (Akt/PKB expression and activation and c-Myc expression), in B16 melanoma tumor cells at baseline and in response to CENU treatment.

We show that PP2A methylation status is tightly linked to PP2A activity, that PP2A is strongly activated during the primary response to DNA damage, and that $\mathrm{PP} 2 \mathrm{~A}$ regulates melanoma tumor cell proliferation through the expression and activation of Akt and c-Myc both at baseline and in response to DNA damage. Our data are in favor of the implication of PP2A methylation in the mechanistics of loss of aggressiveness of B16 melanoma tumor cells and of a potential interest of PP2A methylation as a target for anticancer drug development.

\section{Materials and methods}

Chemicals. Okadaic acid (OA) (Sigma, Saint Quentin Fallavier, France) was prepared as a $100-\mu \mathrm{M}$ stock in dimethyl sulfoxide (DMSO, Sigma). Xylulose-5-phosphate (X5P) was a gift from Dr L. Hecquet (CNRS, UMR6504, Aubiere, France) and was prepared as a $3-\mathrm{mM}$ stock in $0.9 \% \mathrm{NaCl}$. Goat serum used for PTEN activity determination was from Sigma. A member of the CENU drug family, cystemustine (N'-(2chloroethyl)-N-(2-(methylsulphonyl)-ethyl)-N'-nitrosourea) (Orphachem, Clermont-Ferrand, France) was prepared as $5 \mathrm{mM}$ solution in $0.9 \% \mathrm{NaCl}$. L- $\left[{ }^{14} \mathrm{CH}_{3}\right]$-S-adenosylmethionine $\left(\left[{ }^{14} \mathrm{CH}_{3}\right]-\mathrm{SAM}\right)$ (specific activity $55 \mathrm{mCi}^{\mathrm{mmol}}{ }^{-1}$ ) was purchased from Amersham Bioscience (Buckinghamshire, UK). L- $\left[{ }^{13} \mathrm{CH}_{3}\right]$-methionine was purchased from Euriso-Top (Gif sur Yvette, France). TRIzol ${ }^{\circledR}$ reagent was purchased from Sigma. The PP2A immunoprecipitation phosphatase assay kit was purchased from Upstate (Lake Placid, NY). PTEN ELISA kit was from Echelon Biosciences (Salt Lake City, UT).

Cell culture. The transplantable B16 (F1) melanoma cells originating from C57BL6/6J Ico mice were obtained from ICIG (Villejuif, France) and adapted to grow in culture. The cells were maintained as monolayers in culture flasks in Eagle's MEM-glutaMAX medium (Invitrogen, Cergy Pontoise, France) supplemented with $10 \%$ fetal calf serum (Sigma), $1 \mathrm{mM}$ sodium pyruvate, $4 \mu \mathrm{g} / \mathrm{ml}$ gentamycin, $200 \mathrm{mM}$ glutamine, $1 \mathrm{X}$ non-essential amino-acid solution (Invitrogen) and vitamins (Invitrogen).

Cell treatments. B16 melanoma cells were treated by okadaic acid (OA) at $5 \mathrm{nM}$ or by xylulose-5-phosphate (X5P) at $50 \mu \mathrm{M}$ for $48 \mathrm{~h}$, an antagonist (5) and an agonist (18) of PP2A methylation, respectively. After treatments, cells were harvested by trypsinisation, counted and stored at $-80^{\circ} \mathrm{C}$ until analysis. In another set of experiments, B 16 melanoma cells were exposed to CENU (at day 0) for $2 \mathrm{~h}$ at $200 \mu \mathrm{M}$, the culture medium was then rinsed with PBS. For the investigation of global cellular methylations, CENU-treated B16 melanoma cells were incubated with $0.8 \mu \mathrm{Ci} / \mathrm{ml}$ of $\left[{ }^{14} \mathrm{CH}_{3}\right]-\mathrm{SAM}$. After $16 \mathrm{~h}$ of incubation, cells were harvested, counted and stored at $-80^{\circ} \mathrm{C}$ until analysis. Three independent experiments were performed for each conditions. For cell culture labelling with $\mathrm{L}-\left[{ }^{13} \mathrm{CH}_{3}\right]$-methionine, ${ }^{1} \mathrm{H}-{ }^{13} \mathrm{C}$ NMR spectroscopy experiments were performed as previously described (19). In Fig. 1, cell number was determined in each group of cell culture (UN, $\mathrm{OA}$ and $\mathrm{X} 5 \mathrm{P}$ ). The effect of OA and X5P on cell proliferation was determined as follows:

$\frac{\text { Number of treated cells x } 100}{\text { Number of UN cells }}-100$

$\left[{ }^{14} \mathrm{CH}_{3}\right]-S A M$ incorporation in proteins. For methyl groups incorporation in cytoplasmic and nuclear proteins, cells were Dounce homogenized with pestle ' $\mathrm{B}$ ' in a fractionation buffer (10 mM Tris- $\mathrm{HCl} \mathrm{pH} 7.4,10 \mathrm{mM} \mathrm{NaCl}, 3 \mathrm{mM}$ $\mathrm{MgCl}_{2}, 1 \mathrm{mM}$ EDTA) containing protease inhibitor mixture. Complete cell lysis was checked by microscopy with trypan blue. Then lysed cells were centrifuged $(10,000 \mathrm{~g}$ for $10 \mathrm{~min}$ at $4^{\circ} \mathrm{C}$ ). Supernatant was kept as the cytosolic fraction. The pellet was carefully washed with lysis buffer and centrifuged $\left(10,000 \mathrm{~g}\right.$ for $10 \mathrm{~min}$ at $\left.4^{\circ} \mathrm{C}\right)$. The supernatant was added to the cytosolic fraction. The pellet containing nuclei was further disrupted by ultrasonication in fractionation buffer ( 3 times $15 \mathrm{sec}$ in ice) and centrifuged $\left(10,000 \mathrm{~g}\right.$ for $10 \mathrm{~min}$ at $\left.4^{\circ} \mathrm{C}\right)$. The supernatant was kept as the nuclear fraction. Proteins from the cytoplasmic and the nuclear compartments were precipitated by adding 4 volumes of cold acetone to the cytoplasmic and nuclear fractions. The homogenates were vortexed, stored at $-20^{\circ} \mathrm{C}$ for $2 \mathrm{~h}$ and then centrifuged $(14,000 \mathrm{~g}$, $30 \mathrm{~min}$ at $4^{\circ} \mathrm{C}$ ). The pellet containing the precipitated proteins was washed twice in acetone. Then acetone was evaporated under nitrogen stream. The pellets were mixed with $1 \mathrm{M}$ $\mathrm{NaOH}$ and protein concentration was determined. An aliquot of the protein solution was mixed with liquid scintillation cocktail (Packard, Rungis, France), the radioactivity was measured in a scintillation counter (Winspectral Wallac 1414). Radioactivity incorporation was expressed as the percentage of dpm in CENU-treated cells proteins compared to untreated cell dpm values. Data represent three independent experiments.

$\left[{ }^{14} \mathrm{CH}_{3}\right]-S A M$ incorporation in DNA. DNA was extracted by the TRIzol ${ }^{\circledR}$ method according to the manufacturer's instructions and its concentration was determined at $\lambda=260 \mathrm{~nm}$. Then, $5 \mu \mathrm{g}$ of the dissolved DNA was mixed with liquid scintillation cocktail, and the radioactivity was measured in a scintillation counter. Radioactivity incorporation was expressed as the percentage of dpm in CENU-treated cells proteins compared to dpm values in untreated cells. Data represent three independent experiments.

Methylation of proteins assayed by ${ }^{1} \mathrm{H}^{13} \mathrm{C}$ NMR spectroscopy. Using a step-labeling experiment similar to that of the radioactivity section, but using stably labeled $\mathrm{L}-\left[{ }^{13} \mathrm{CH}_{3}\right]$ methionine 
and ${ }^{1} \mathrm{H}-{ }^{13} \mathrm{C}$ NMR spectroscopy, we recently demonstrated post-translational methylation of proteins, mainly histones, in a B16 melanoma model (19). The technique was used to quantify the ratio of the signal of methylated residues in proteins (asymmetrical dimethyl-arginine, dimethyl-lysine and trimethyl-lysine) to the signal of methionine incorporated in proteins, in untreated and CENU-treated B16 melanoma cells. Because observed methylations mostly concerned histones, the proposed ratio represented the amount of nuclear protein methylations relative to cellular total proteins in tumor cells.

Total cell protein extracts and protein concentration. Intact cells were lysed in a lysis buffer $(50 \mathrm{mM}$ Tris $\mathrm{HCl} \mathrm{pH} 8.0$, $100 \mathrm{mM} \mathrm{NaCl}$ ) containing protease inhibitor mixture (Roche, Mannheim, Germany) by ultrasonication (3 times $15 \mathrm{sec}$ in ice). After centrifugation $(14,000 \mathrm{~g}$ for $10 \mathrm{~min}$ at $\left.4^{\circ} \mathrm{C}\right)$, the supernatant was kept at $-80^{\circ} \mathrm{C}$ until analysis. Protein concentration was determined with Commassie Blue (Invitrogen) at $\lambda=595 \mathrm{~nm}$ with bovine albumin serum as standard.

Western blotting. Proteins from total cells were subjected to SDS-PAGE on 10\% SDS-polyacrylamide gel electrophoresis and transferred onto Immobilon-NC membrane (Millipore, Saint Quentin en Yvelines, France). The membranes were blocked with Tris-buffered saline containing $0.1 \%$ Tween-20 (TBST) and 4\% non-fat milk for 60 min and probed with antibodies against non-methylated PP2AC $(1: 2,500)$, methylated PP2AC (PP2AC-Met+) (1:250), PP1 (1:2,000) (Upstate), Akt $(1: 2,000)$, phosphorylated Akt or P-Akt $\left(\operatorname{Ser}^{473}\right)(1: 1,000)$, PTEN $(1: 2,000)$, phosphorylated PTEN or P-PTEN $\left(\right.$ Ser $\left.^{380} / \mathrm{Thr}^{382 / 383}\right)(1: 2,000)$ (Cell Signaling, Danvers, MA), c-Myc (1:200) (Santa Cruz Biotechnology, Le Perray en Yvelines), and B-tubulin (1:2,500) (Sigma) overnight at $4^{\circ} \mathrm{C}$ and washed three times with TBST. The membrane was probed with horseradish peroxidase-conjugated secondary antibodies (Upstate) at 1:2,000 (PP2AC-Met+, PP1, Akt, P-Akt, PTEN, P-PTEN, c-Myc) or 1:2,500 (PP2AC, B-tubulin) for $1 \mathrm{~h}$ at room temperature and washed with TBST three times. The immunoblots were visualized by enhanced chemiluminescence (Amersham Bioscience). Densitometrical measurement of the band of interest was done using the Quantity One software (Bio-Rad). Normalization was done using ß-tubulin densitometrical values. All the results shown are representative of three independent experiments.

PP2A in vitro protein phosphatase assay. A PP2A immunoprecipitation phosphatase assay kit (Upstate) was used to detect PP2A activity according to the manufacturer's instructions. In brief, PP2A was immunoprecipitated with a monoclonal anti-PP2A antibody and protein A-Sepharose beads in lysis buffer. PP2A-bound beads were washed with phosphatase assay buffer and then with pNPP serine/threonine assay buffer (50 mM Tris $\mathrm{HCl}, 100 \mathrm{mM} \mathrm{CaCl}_{2}, \mathrm{pH} 7.0$; Upstate). Diluted phosphopeptide (K-R-pT-I-R-R) in serine/ threonine assay buffer $(250 \mu \mathrm{M})$ was added and then incubated for $15 \mathrm{~min}$ at $30^{\circ} \mathrm{C}$. After centrifugation, $25 \mu \mathrm{l}$ of supernatant was transferred to an assay plate, and $100 \mu 1$ of Malachite Green phosphate detection solution was added for $15 \mathrm{~min}$ incubation at $30^{\circ} \mathrm{C}$. The relative absorbance was measured at $\lambda=630 \mathrm{~nm}$. Results are from two independent experiments that were performed in duplicate.

PTEN in vitro lipid phosphatase assay. An ELISA assay was used to detect PTEN activity according to the manufacturer's instructions. This kit allows to measure the transformation of $\mathrm{PI}(3,4,5) \mathrm{P}_{3}$ into $\mathrm{PI}(4,5) \mathrm{P}_{2}$ by PTEN lipid phosphatase activity by spectrophotometric detection. PTEN was immunoprecipitated using protein A-Sepharose beads with antiPTEN antibody (Cell Signaling) in lysis buffer for $2 \mathrm{~h}$ at $4^{\circ} \mathrm{C}$. The beads were washed three times with TBS and once with PTEN enzyme reaction buffer (10 mM HEPES, $150 \mathrm{mM}$ $\mathrm{NaCl}, 10 \mathrm{mM}$ DTT, pH 7.2). Then, $100 \mu \mathrm{l}$ of PTEN enzyme reaction buffer was added and the beads were transferred to an assay plate where the substrate $\left(\mathrm{PI}(3,4,5) \mathrm{P}_{3}\right)$ was coated in the bottom of each well. After incubating the plate for $1 \mathrm{~h}$ at $37^{\circ} \mathrm{C}$, the beads were discarded and the wells were washed three times with $200 \mu 1$ of TBST. Then, the $\mathrm{PI}(4,5) \mathrm{P}_{2}$ detector complex was prepared by dissolving one detector pellet in TBS containing $1 \%$ goat serum (TBSGS) $(10.5 \mathrm{ml}$ of TBSGS and $10.5 \mu 1$ of co-detector solution). Then $100 \mu 1$ of $\mathrm{PI}(4,5) \mathrm{P}_{2}$ detector complex were added by well and the plate was incubated for $1 \mathrm{~h}$ at room temperature under gentle agitation. The detector complex was discarded and the wells were washed three times with TBST. The secondary antibody (260 $\mu \mathrm{l}$ of enzyme-linked antibody mixed in $10.25 \mathrm{ml}$ of TBSGS) was added (100 $\mu \mathrm{l} /$ well). The plate was incubated for $1 \mathrm{~h}$ at room temperature under gentle agitation and the wells were washed three times with TBST. Then, $100 \mu 1$ of TMB were added per well and the plate was incubated at room temperature until the color development was sufficient for photometric analysis. The reaction was stopped with $50 \mu 1$ per well of $0.5 \mathrm{M}$ sulfuric acid. The absorbance in each well was read with a plate reader at $\lambda=450 \mathrm{~nm}$. Results are from two independent experiments that were performed in duplicate.

Statistical analysis. In all experiments, data are given as mean \pm standard deviation (SD). Comparison between groups was performed using the Mann-Whitney $U$ test and $\mathrm{p}<0.05$ was considered as significant. Linear regression was used to show correlation between PP2A methylation, PP2A activity and the retained criteria of aggressiveness (proliferation rate, $\mathrm{P}-\mathrm{Akt}$ and c-Myc expression).

\section{Results}

Okadaic acid inhibits PP2A methylation and activity, and increases Akt and c-Myc in B16 melanoma cells. PP2A activity is regulated by the methylation of its catalytic subunit. In turn $\mathrm{PP} 2 \mathrm{~A}$ regulates the Akt/PKB pathway, which is involved in cell proliferation, protein synthesis, resistance to apoptosis (2). This pathway is often hyperactivated in cancer (3).

OA, at low dose $(5 \mathrm{nM})$, is a PP2A antagonist and demethylating agent (5). At this dose, OA has been reported to increase cell proliferation (20). In our experiment, OA at $5 \mathrm{nM}$ slightly stimulated cell growth $(+30 \%, \mathrm{p}<0.05)$ when compared to untreated cells (UN) (Fig. 1A). As shown in Fig. 1B, OA partially inhibited methylation of PP2AC few days after exposure. OA treatment did not alter the expression 
A

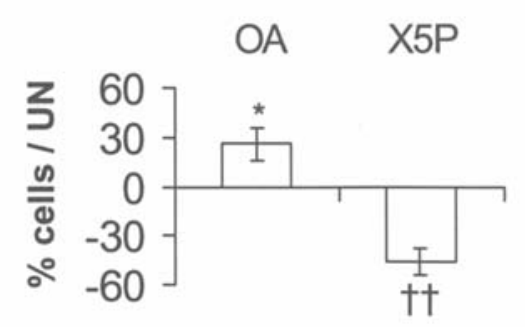

C

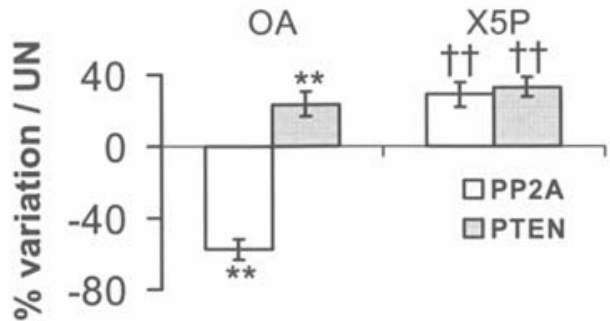

B

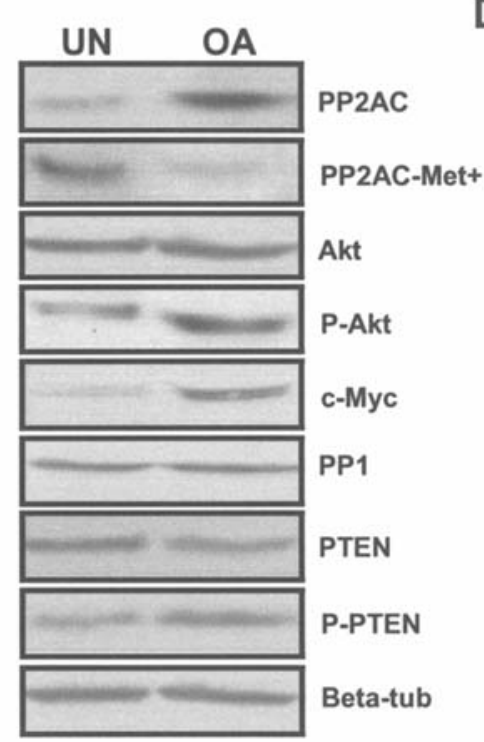

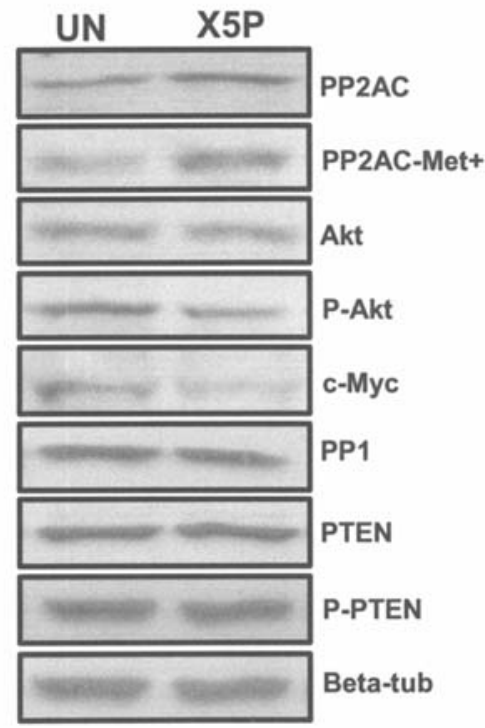

Figure 1. Effect of an antagonist (OA) and an agonist (X5P) of PP2A methylation on untreated B16 melanoma cell proliferation, phosphatase and oncoprotein expression and phosphatase activities. A, OA treatment stimulated cell proliferation whereas X5P treatment inhibited cell growth. B, Western blot analysis of OA treatment on the expression of non-methylated PP2AC (PP2AC), methylated PP2AC (PP2AC-Met+), Akt, P-Akt, c-Myc, PTEN, P-PTEN, PP1 and B-tubulin. C, Effect of OA and X5P treatments on PP2A and PTEN activities. D, Western blot analysis of X5P treatment on the expression of non-methylated PP2AC (PP2AC), methylated PP2AC (PP2AC-Met+), Akt, P-Akt, c-Myc, PTEN, P-PTEN, PP1 and B-tubulin. A, Cells were treated either by OA at 5 nM or by X5P at $50 \mu \mathrm{M}$ for $48 \mathrm{~h}$; at the end of the treatment, cells were harvested and counted. B and D, Equal protein loading was verified by Ponceau S staining of the membrane and by B-tubulin expression. All the experiments are representative of three independent experiments. C, PP2A and PTEN activities were determined as described in Materials and methods. Columns, mean of 2 independent experiments; bars, SD. ${ }^{*} \mathrm{p}<0.05, \mathrm{OA}$ vs $\mathrm{UN}$; ${ }^{* *} \mathrm{p}<0.01, \mathrm{OA}$ vs UN; ${ }^{\dagger} \mathrm{p}<0.01, \mathrm{X} 5 \mathrm{P}$ vs UN.

of protein phosphatase 1 (PP1) and Akt expression but increased the relative amount of the activated form of Akt (phosphorylated Akt, P-Akt) and c-Myc expression (Fig. 1B). The relative amount of the active form of PTEN was decreased whereas the inactive form of PTEN, phosphorylated PTEN (P-PTEN), was increased, as shown in Fig. 1B. Then, we measured PP2A and PTEN activities. OA decreased PP2A activity by $>50 \%$ (Fig. 1C) and, surprisingly, increased PTEN lipid phosphatase activity by $25 \%$ (Fig. 1C). The low dose of OA used in our experiment selectively targeted PP2A because PP1 expression was not modified (Fig. 1B). Taken together, these results confirm the tumor-promoting effect of OA through PP2A demethylation (21).

Xylulose-5-phosphate increases PP2A methylation and activity and decreases Akt and c-Myc in B16 melanoma cells. X5P, at $50 \mu \mathrm{M}$, was reported to be an agonist of PP2A methylation in vitro (18). At this dose, $\mathrm{X} 5 \mathrm{P}$ strongly decreased cell growth of B16 melanoma cells $(-46 \%, \mathrm{p}<0.01$, Fig. 1A). As shown in Fig. 1D, the methylation of PP2AC was increased, but PP1 expression was not affected neither the Akt expression. However, after $48 \mathrm{~h}$ of treatment with X5P, P-Akt levels and c-Myc expression were decreased (Fig. 1D). PTEN and P-PTEN relative amounts were not altered. X5P increased the activity of PP2A by $30 \%$ and the activity of PTEN by $35 \%$ (Fig. 1C).

Untreated B16 melanoma cells showed an accumulation of P-Akt, Akt and c-Myc proteins in comparison with normal human melanocytes (data not shown). These oncoproteins have been reported to play a key role in the abnormal proliferation of melanoma tumor cells $(2,3)$.

Data using PP2A methylating and demethylating agents demonstrate that PP2A methylation status controls tumor cell proliferation and oncoprotein expression and activation.

Methylation disorders in response to DNA damage induced by chloroethylnitrosourea. We next investigated PP2A methylation in tumor cells in response to DNA damage. This model was established by treating B16 melanoma cells with chloroethylnitrosourea (CENU). CENU treatment is known to induce DNA damage and global DNA hypomethylation 
A

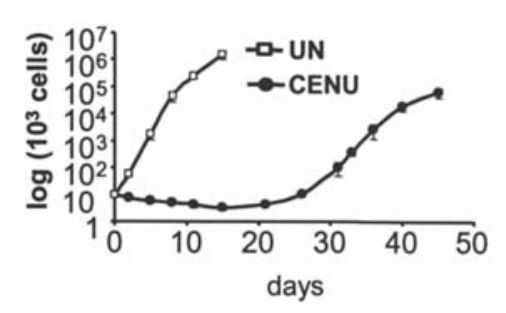

C

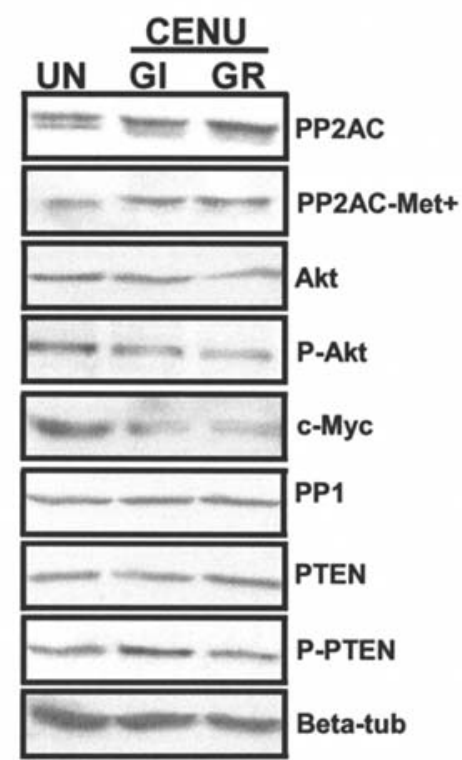

B

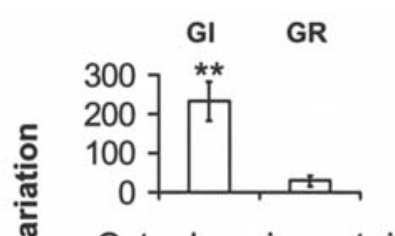

Cytoplasmic proteins

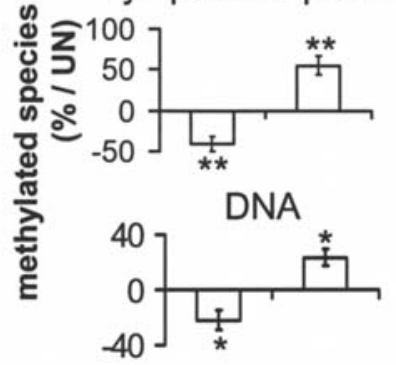

Nuclear proteins

D

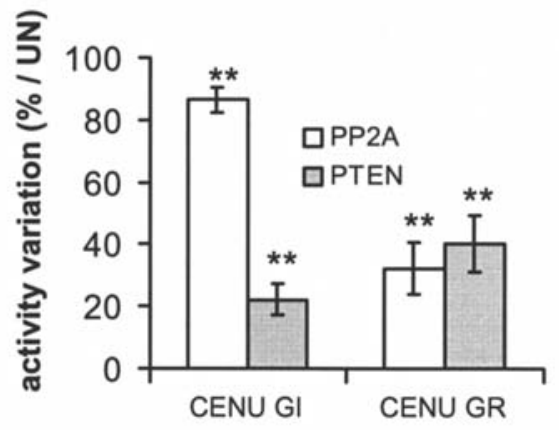

Figure 2. Response of B16 melanoma cells to CENU treatment on cell proliferation, global protein and DNA methylation, phosphatase and oncoprotein expression and phosphatase activities. A, Cell proliferation curves. B16 melanoma cells were treated by CENU (200 $\mu \mathrm{M}, 2 \mathrm{~h})$ at day 0 . Cell proliferation was followed for 45 days. B, Impact of CENU treatment on cytoplasmic and nuclear protein methylation and on DNA methylation. Methyl group incorporation in CENU-treated cells was determined as described in Materials and methods. Columns, mean of 3 independent experiments; bars, SD. C, Western blot analysis of the effect of CENU treatment on the expression of non-methylated PP2AC (PP2AC), methylated PP2AC (PP2AC-Met+), Akt, P-Akt, c-Myc, PTEN, PPTEN, PP1 and B-tubulin. Equal protein loading was verified by Ponceau S staining of the membrane and by B-tubulin expression. Results are representative of three independent experiments. D, Effect of CENU treatment on PP2A and PTEN activities. PP2A and PTEN activities were determined as described in Materials and methods. In graphics from B and D, variables are the variations with respect to UN, normalized to UN. Columns, mean of two independent experiments; bars, SD. ${ }^{*} \mathrm{p}<0.05, \mathrm{CENU}$ vs UN; ${ }^{* *} \mathrm{p}<0.01, \mathrm{CENU}$ vs UN.

(11). In response to this treatment, it was previously shown that proliferation evolved in two phases, a growth inhibitory (GI) and growth recovery (GR) phases (Fig. 2A) (13). Cell morphology, cell cycle distribution, nuclear aberrations, DNA damage and metabolism alterations of these cells during the GI and the GR phases have been previously reported (11-13,22-24). These cells demonstrated decreased aggressiveness and redifferentiation during both phases: accumulation in $G_{1}$ phase of the cell cycle during the growth GR phase, increased pool of PUFA, acquired metabolic alteration (phospholipid, methionine, energetic metabolism), decreased pool of glutathione (11-13,22-24).

It has been reported that the methylation of PP2A catalytic subunit was the most important methyl group consumer among the cellular proteins $(14,17,25)$. To see whether PP2A methylation in our model correlated with DNA and global protein methylation disorders, we performed pulse-chase labeling experiments using S-adenosyl-L- $\left[{ }^{14} \mathrm{CH}_{3}\right]$ methionine and L- $\left[{ }^{13} \mathrm{CH}_{3}\right]$ methionine (Fig. 2B). During the GI phase, there was an increase in the incorporation of methyl groups into cytoplasmic proteins (2-fold, vs UN cells) (Fig. 2B, top), whereas methyl incorporation into DNA was decreased by $40 \%$ ( $<<0.01$, Fig. 2B, middle). Data obtained by NMR spectroscopy analysis showed a decrease in the incorporation of methyl groups into nuclear proteins (Fig. 2B, bottom). During the GR phase, there was a slight increase of cytoplasmic protein methyl incorporation (Fig. 2B, top) but an increase in DNA methyl incorporation $(+55 \%, \mathrm{p}<0.01)$ and nuclear proteins $(+25 \%, \mathrm{p}<0.05)$ (Fig. $2 \mathrm{~B}$, middle and bottom). Taken together, these data show that CENU-induced DNA damage induces methylation disorders in DNA and proteins, and that PP2A methylation follows global cytoplasmic protein methylation (see below).

DNA damage induced by CENU increases PP2A methylation and activity and decreases Akt and c-Myc. Fig. 2C shows that, during the GI phase, PP2AC was more expressed and that its methylation was increased in comparison with UN cells. During the GR phase, PP2AC was even more methylated than in UN cells (Fig. 2C). 
A

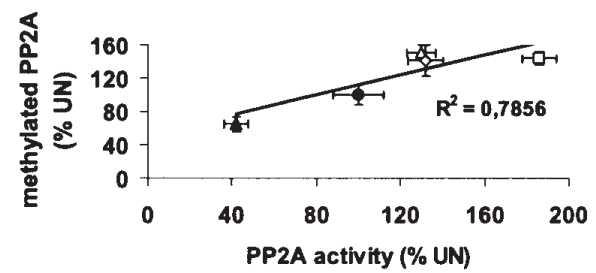

B

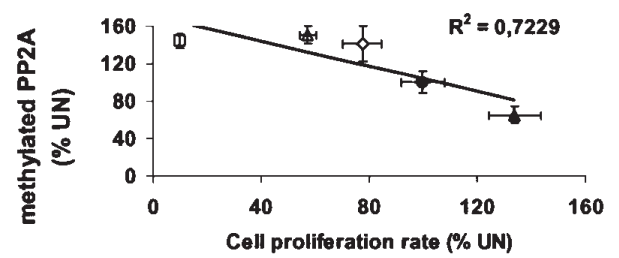

UN

$\triangle \mathrm{X} 5 \mathrm{P}$

CENU GI

$\triangle O A$

C

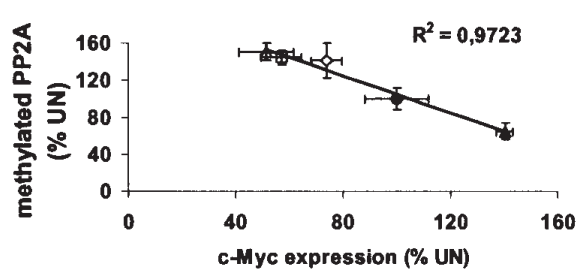

D

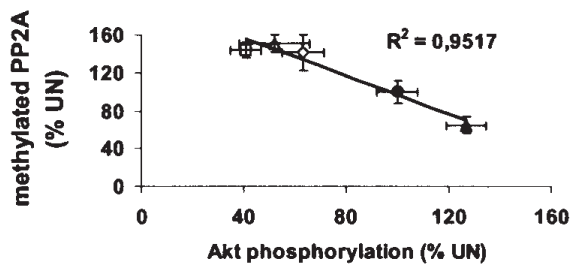

Figure 3. Relationship between PP2A methylation, PP2A activity and criteria of tumor cell aggressiveness. A, PP2A activity; B, Cell proliferation rate (expressed in percentage of UN); C, Phosphorylation of Akt (expressed in percentage of UN); D, c-Myc expression (expressed in percentage of UN). All criteria of aggressiveness (B-D) were highly and negatively correlated to PP2A methylation (expressed in percentage of the methylated form of UN). In the graphics, variables are the percentage of UN values.

During the GI phase (Fig. 2C), there was a decreased expression of Akt and c-Myc. Akt activation was diminished as represented by the fall of P-Akt level. In the meanwhile, there was a slight increase of PP1 expression and a strong increase of PTEN phosphorylation as shown in Fig. 2B. During the GR phase, most of these alterations remained. However there was a decrease of PTEN phosphorylation in comparison to UN cells, suggesting an activation of PTEN lipid phosphatase activity (Fig. 2C). PP1 protein level returned to base line expression during the GR phase (Fig. 2C).

PP2A and PTEN phosphatase activities were measured. Both PP2A and PTEN activities were increased, by $85 \%$ and $20 \%(\mathrm{p}<0.01)$ during the GI phase and by $35 \%$ and $40 \%$ $(\mathrm{p}<0.01)$ during the GR phase, respectively (Fig. 2D, top). Altogether these data show that the response to CENU-induced DNA damage is in part mediated by the increase of PP2A methylation and activity.

Correlation between PP2A methylation status, PP2A activity and oncoprotein expression in B16 melanoma. There is a constant need to discover biomarkers for the evaluation of tumor cell aggressiveness, response to treatment and prediction of the response. We thus tried to correlate PP2A methylation status (expressed in percentage of PP2A methylation of UN) to PP2A activity and to the following parameters: rate of proliferation, Akt phosphorylation, and c-Myc expression (also expressed in percentage of expression of UN cells). For PP2A methylation status, Akt phosphorylation and c-Myc expression, we measured the relative intensity of each band from the Western blotting and normalized it with measured

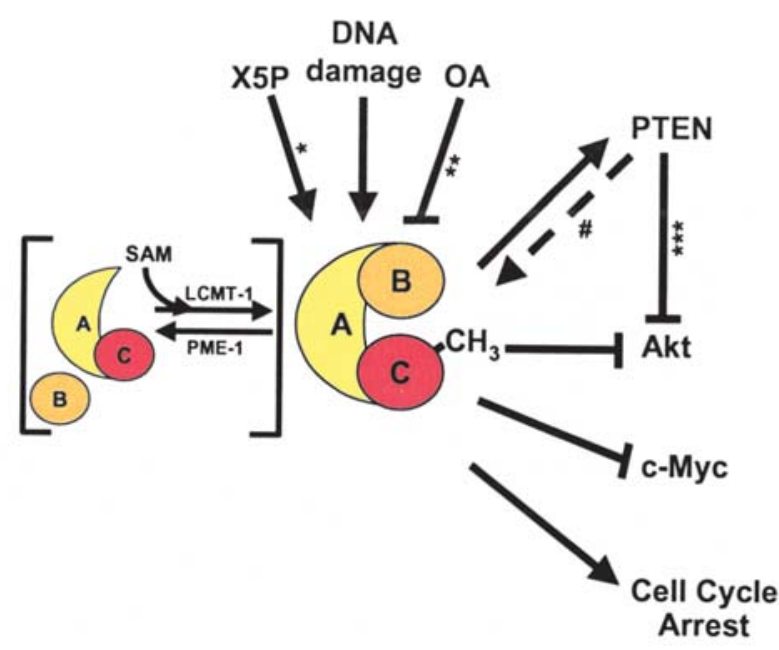

Figure 4. Interpretation and findings on the regulation of PP2A activity and function by methylation. X5P treatment increases PP2A methylation. OA treatment inhibits PP2A methylation. At the biochemical level, PP2A methylation results from the opposing effects of specific leucine methyltransferase (LCMT-1) or protein phosphatase methylesterase (PME-1). DNA damage induces PP2A methylation. Full lines, data from this work; asterisks, data strongly supported by the literature $\left[{ }^{*}(18) ;{ }^{* *}(20) ;{ }^{* * *}(30)\right]$; "hypothetical interaction between PP2A and PTEN (see Discussion).

ß-tubulin relative intensity. Regression analysis presented in Fig. 3, showed positive and significant linear relationships between PP2A methylation and PP2A activity $\left(\mathrm{R}^{2}=0.7856\right)$ in all used models and negative and significant linear relationships between PP2A methylation and tumor cell aggressiveness 
criteria (proliferation rate, $\mathrm{R}^{2}=0.7229, \mathrm{p}<0.05$; $\mathrm{P}-\mathrm{Akt}, \mathrm{R}^{2}=$ 0.9517; $\mathrm{p}<0.01, \mathrm{c}-\mathrm{Myc}, \mathrm{R} 2=0.9723, \mathrm{p}<0.05)$.

\section{Discussion}

This report demonstrates that in B16 melanoma cells: i) PP2A methylation status is tightly linked to PP2A activity; ii) PP2A regulates melanoma tumor cell proliferation through the downregulation of oncoproteins; and iii) PP2A is strongly activated during the primary response to DNA damage. In addition we show that PP2A methylation status is indicative of the degree of tumor cell aggressiveness.

There are conflicting results on the relationship between PP2A methylation and activity. A decrease of PP2A activity with increased PP2A methylation has been reported (26). However, these authors acknowledged that it was uncertain whether the direct cause of PP2A decreased activity was due the carboxyl-methylation itself. Other reports state that methylation was necessary for PP2A activation $(5,6,17)$. Our data show that PP2A methylation was strongly correlated with PP2A activity. This is in agreement with the bulk of literature data $(5,6,17,25)$. Moreover, the amplitude of PP2A activity variations that we found were in agreement with another report stating an increase of PP2A activity between 31 and 54\% when purified catalytic subunit of PP2A from breast cancer cells where exposed to a mixture of methyltransferases (27).

PP2A methylation was shown to be strongly decreased in tumor cells $(5,6)$. However, the link between PP2A methylation and oncoprotein expression has not been established yet. PP2A has multiple molecular targets (5), among which the protein kinase Akt. The Akt/PKB pathway is implicated in cell proliferation, protein synthesis, resistance to apoptosis and is often mutated in cancer $(2,3)$. PP2A is one of the major regulatory protein of the Akt/PKB pathway. PP2A inactivates Akt by dephosphorylation $(1,2,28)$.

We found that PP2A methylation induced by an agonist (X5P) decreased cell proliferation, Akt activation and c-Myc expression. Conversely, the PP2A demethylation by an antagonist (OA) stimulated cell growth and oncoprotein activation or expression. Furthermore, activating PP2A also increased PTEN. The regulatory role of Akt signaling pathway is shared with PTEN whose role in carcinogenesis has been documented $(29,30)$. The implication of PP2A in the regulation of PTEN activation is reported herein for the first time in a tumor cell line although it was recently reported in response to viral infection (31). The increased expression of the active form of PTEN and the increase in the methylation of PP2A strongly suggested a downregulation of the Akt pathway.

The real mechanism involving PTEN activation by PP2A remained unclear. However, from our results and the data from the literature, we can suggest that there might be an interaction between PTEN and PP2A. Both PTEN and PP2A are regulators of the Akt pathway and their cellular localization is very close. PTEN can be phosphorylated on multiple Thr and Ser sites $(32,33)$. Some of these sites could be potential substrates for PP2A. Moreover PTEN was reported to express a protein tyrosine phosphatase activity $(34,35)$. Then activated PP2A could dephosphorylate PTEN which would in turn dephosphorylate PP2AC on $\mathrm{Tyr}^{307}$ allowing PP2A to be more active. Thus, methylating PP2A would lead two tumor suppressor proteins to be activated.

Our data showed that PTEN activity was increased in response to OA treatment despite the decrease of $\mathrm{PP} 2 \mathrm{~A}$ activity. It has been shown recently that PTEN ubiquitination was necessary for its nuclear localization and function (36). Moreover, in neuronal cells, it was reported that inhibiting PP2A methylation increased the levels of ubiquitinated proteins such as tau protein $(37,38)$. Thus, inhibiting PP2A methylation might allow PTEN nuclear translocation and ubiquitination.

CENU is a well known DNA damaging agent that preferentially targets guanine at the $\mathrm{O}^{6}$ position (11). An important part of DNA damage lesions induced by alkylating agents, such as CENU, are repaired by methylguanine-N-methyltransferase (MGMT). Nevertheless, untreated B 16 melanoma cells do not express this DNA repair protein. But it was shown that fotemustine, another nitrosourea, induced the re-expression of the MGMT gene (39). Moreover, the inactivation of Akt following DNA damage could lead to the activation of p53 (40) which was shown to upregulate MGMT expression (41). This might have taken part in growth recovery of CENU-treated B16 melanoma cells.

During this phase CENU-treated cells also exhibited signs of melanocytic differentiation and decreased aggressiveness. This differentiated phenotype was characterized by an increase in cellular polyunsaturated fatty acid (PUFA) content, probably in response to the activation of phospholipases $A_{2}$ (13). PUFA are precursors for de novo synthesis of ceramide, which are PP2A activators (42), and may participate in the activation of $\mathrm{PP} 2 \mathrm{~A}$ in response to CENU treatment.

In a recent study, $\mathrm{PP} 2 \mathrm{~A}$ was shown to participate in the response to doxorubucin or $\gamma$-irradiation by dephosphorylating Polo-like kinase-1, thus inducing cell cycle arrest in the $G_{2}$ phase (7). Our findings of PP2A methylation increase in response to $\mathrm{CENU}$ treatment is consistent with previous reports showing that CENU treatment induced a $G_{2}$ phase cell cycle arrest in B16 melanoma cells $(11,13)$.

The Akt pathway is implicated in cell proliferation, and cell survival (2-4). Moreover, Akt activation was shown to protect from $\mathrm{G}_{2}$ arrest induced by methylating agent, temozolomide (43). We found a downregulation of Akt and a $G_{2}$ arrest (13) in response to CENU treatment. These results are in agreement with the activation of PP2A induced by CENU treatment. The adjunction of OA during the GI phase induced by CENU treatment completely abrogated the activation of PP2A and its consequences (inactivation of Akt, decreased expression of c-Myc) and decreased the duration of the GI phase (data not shown).

Also, according to the work of Lee et al (17) on methylated species, PP2A methylation status should mainly reflect the activity of the specific methylesterase. The response to DNA damage would principally involve methylesterase activity thus PP2A demethylation. The increased methylation of nuclear proteins could follow the partial inactivation of Akt by PP2A. It was shown that the phosphorylation of EZH2, a histone methyltransferase, by Akt decreased its ability to trimethylate its substrate, lysine 27 in histone $\mathrm{H} 3$, resulting in the derepression of silenced genes, such as oncogenes (44). 
By inactivating Akt, PP2A would let histone H3 be methylated. This would in turn silence oncogenes or allow a tumor suppressor gene to be expressed.

The genomic region of the c-myc gene is very sensitive to alkylating agents (45). c-Myc is involved in tumor cell proliferation, cell survival, and regulates glucose metabolism (46). We found a downregulation of c-Myc in response to DNA damage induced by CENU treatment. This is consistent with the report that PP2A induced the proteasome-dependent degradation of c-Myc (47). In addition c-Myc donwnregulation was linked to low glutathione level (48), in agreement with our previous report of decreased cell glutathione content in response to CENU treatment (13).

A summary of our molecular findings is given in Fig. 4: PP2A methylation agonist and antagonist modulate PP2A activity and oncoprotein expression. DNA damage induces PP2A methylation which inactivates Akt, downregulates cMyc and activates PTEN.

In conclusion, this study demonstrated that, in B16 melanoma cells: i) PP2A methylation status is tightly linked to $\mathrm{PP} 2 \mathrm{~A}$ activity; ii) $\mathrm{PP} 2 \mathrm{~A}$ regulates melanoma tumor cell proliferation through the downregulation of oncoproteins; and iii) PP2A is strongly activated during the primary response to DNA damage. In addition PP2A methylation status and activity correlate to the degree of tumor cell aggressiveness. It follows from these data that agents with PP2A promethylating activity might be candidates for anticancer drug development.

\section{Acknowledgements}

Samuel Guénin is a recipient of a fellowship of Region Auvergne and INSERM. This work has been supported by Biorebus Society.

\section{References}

1. Janssens V and Goris J: Protein phosphatase 2A: a highly regulated family of serine/threonine phosphatases implicated in cell growth and signaling. Biochem J 353: 417-439, 2001.

2. Bellacosa A, Kumar CC, Di Cristofano A and Testa JR: Activation of Akt kinases in cancer: implication for therapeutic targeting. Adv Cancer Res 94: 29-86, 2005.

3. Altomare DA and Testa JR: Perturbations of the AKT signaling pathway in human cancer. Oncogene 24: 7455-7464, 2005.

4. Tokunaga E, Kimura Y, Oki E, et al: Akt is frequently activated in HER2/neu-positive breast cancers and associated with poor prognosis among hormone-treated patients. Int J Cancer 118: 284-289, 2006.

5. Janssens V, Goris J and van Hoof C: PP2A: the expected tumor suppressor. Curr Opin Genet Dev 15: 34-41, 2005.

6. Arroyo JD and Hahn WC: Involvement of PP $2 \mathrm{~A}$ in viral and cellular transformation. Oncogene 24: 7746-7755, 2005

7. Jang YJ, Ji JH, Choi YC, Ryu CJ and Ko SY: Regulation of Polo-like kinase 1 by DNA damage in mitosis: inhibition of mitotic plk-1 by protein phosphatase $2 \mathrm{~A}$. J Biol Chem 282: 2473-2482, 2007

8. Sancar A, Lindsey-Boltz LA, Unsal-Kacmaz K and Linn S: Molecular mechanisms of mammalian DNA repair and the DNA damage checkpoints. Annu Rev Biochem 73: 39-85, 2004.

9. Coutts AS and La Thangue N: The p53 response during DNA damage: impact of transcriptional cofactors. Biochem Soc Symp 73: 181-189, 2006.

10. Roos WP and Kaina B: DNA damage-induced cell death by apoptosis. Trends Mol Med 12: 440-450, 2006.

11. Godeneche D, Rapp M, Thierry A, Laval F, Madelmont JC, Chollet $P$ and Veyre A: DNA damage induced by a new 2chloroethyl nitrosourea on malignant melanoma cells. Cancer Res 50: 5898-5903, 1990.
12. Morvan D, Demidem A, Papon J and Madelmont JC: Quantitative HRMAS proton total correlation spectroscopy applied to cultured melanoma cells treated by chloroethyl nitrosourea: demonstration of phospholipid metabolism alterations. Magn Reson Med 49: 241-248, 2003.

13. Demidem A, Morvan D and Madelmont JC: Bystander effects are induced by CENU treatment and associated with altered protein secretory activity of treated tumor cells. A relay for chemotherapy? Int J Cancer 116: 992-1004, 2006.

14. Grillo MA and Colombatto S: S-adenosylmethionine and protein methylation. Amino Acids 28: 357-362, 2005.

15. Bedford MT and Richard S: Arginine methylation an emerging regulator of protein function. Mol Cell 18: 263-272, 2005.

16. Xie $\mathrm{H}$ and Clarke $\mathrm{S}$ : Protein phosphatase $2 \mathrm{~A}$ is reversibly modified by methyl esterification at its C-terminal leucine residue in bovine brain. J Biol Chem 269: 1981-1984, 1994.

17. Lee J, Chen Y, Tolstykh T and Stock J: A specific protein carboxyl methylesterase that demethylates phosphoprotein phosphatase $2 \mathrm{~A}$ in bovine brain. Proc Natl Acad Sci USA 93: 6043-6047, 1996.

18. Kabashima T, Kawaguchi T, Wadzinski BE and Uyeda K: Xylulose 5-phosphate mediates glucose-induced lipogenesis by xylulose 5-phosphate-activated protein phosphatase in rat liver. Proc Natl Acad Sci USA 100: 5107-5112, 2003.

19. Morvan D, Demidem A, Guénin S and Madelmont JC: The methionine-dependence phenotype of tumors: metabolite profiling in a melanoma model using L-[methyl- $\left.{ }^{13} \mathrm{C}\right]$ methionine and HRMAS ${ }^{1} \mathrm{H}_{-}{ }^{13} \mathrm{C}$ NMR spectroscopy. Magn Reson Med 55: 984-996, 2006.

20. Baharians Z and Schönthal A: Reduction of Ha-ras-induced cellular transformation by elevated expression of protein phosphatase type 2A. Mol Carcinog 24: 246-254, 1999.

21. Fujiki H, Suganuma M, Yoshizawa S, Nishiwaki S, Winyar B and Sugimura T: Mechanisms of action of okadaic acid class tumor promoters on mouse skin. Environ Health Perspect 93: 211-214, 1991 .

22. Buchdahl C, Papon J, Communal Y, Bourges $M$ and Madelmont JC: G2 accumulation and melanin overproduction in malignant melanocytes treated with a new nitrosourea. Melanoma Res 8: 517-527, 1998.

23. Demidem A, Morvan D, Papon J, De Latour M and Madelmont JC: Cystemustine induces redifferentiation of primary tumors and confers protection against secondary tumor growth in a melanoma murine model. Cancer Res 61: 2294-2300, 2001 .

24. Morvan D, Demidem A, Papon J, De Latour M and Madelmont JC: Melanoma tumors acquire a new phospholipid metabolism phenotype under cystemustine as revealed by highresolution magic angle spinning proton nuclear magnetic resonance spectroscopy of intact tumor samples. Cancer Res 62: 1890-1897, 2002.

25. Lee $\mathrm{J}$ and Stock $\mathrm{J}$ : Protein phosphatase $2 \mathrm{~A}$ catalytic subunit is methyl-esterified at its carboxyl terminus by a novel methyltransferase. J Biol Chem 268: 19192-19195, 1993.

26. Zhu T, Matsuzawa S, Mizuno Y, et al: The interconversion of protein phosphatase $2 \mathrm{~A}$ between $\mathrm{PP} 2 \mathrm{~A}_{1}$ and $\mathrm{PP} 2 \mathrm{~A}_{0}$ during retinoic acid-induced granulocytic differentiation and a modification on the catalytic subunit in S phase of HL-60 cells. Arch Biochem Biophys 339: 210-217, 1997.

27. Favre B, Zolnierowicz S, Turowski P and Hemmings BA: The catalytic subunit of protein phosphatase $2 \mathrm{~A}$ is carboxylmethylated in vivo. J Biol Chem 269: 16311-16317, 1994.

28. Kowluru A, Seavey SE, Rabaglia ME, Nesher R and Metz SA: Carboxylmethylation of the catalytic subunit of protein phosphatase 2A in insulin-secreting cells: evidence for functional consequences on enzyme activity and insulin secretion. Endocrinology 137: 2315-2322, 1996.

29. Stahl JM, Cheung M, Sharma A, Trivedi NR, Shanmugam S and Robertson GP: Loss of PTEN promotes tumor development in malignant melanoma. Cancer Res 63: 2881-2890, 2003.

30. Wu H, Goel V and Haluska FG: PTEN signaling pathways in melanoma. Oncogene 22: 3113-3122, 2003.

31. Pim D, Massimi P, Dilworth SM and Banks L: Activation of the protein kinase B pathway by the HPV-16 E7 oncoprotein occurs through a mechanism involving interaction with PP2A. Oncogene 24: 7830-7838, 2005.

32. Miller SJ, Lou DY, Seldin DC, Lane WS and Neel BG: Direct identification of PTEN phosphorylation sites. FEBS Lett 528: 145-153, 2002.

33. Gericke A, Munson M and Ross AH: Regulation of the PTEN phosphatase. Gene 374: 1-9, 2006. 
34. Li J, Yen C, Liaw D, et al: PTEN, a putative protein tyrosine phosphatase gene mutated in human brain, breast, and prostate cancer. Science 275: 1943-1947, 1997.

35. Cai XM, Tao BB, Wang LY, et al: Protein phosphatase activity of PTEN inhibited the invasion of glioma cells with epidermal growth factor receptor mutation type III expression. Int J Cancer 117: 905-912, 2005.

36. Trotman LC, Wang X, Alimonti A, et al: Ubiquitination regulates PTEN nuclear import and tumor suppression. Cell 128: 141-156, 2007.

37. Kins S, Crameri A, Evans DR, Hemmings BA, Nitsch RM and Gotz J: Reduced protein phosphatase 2A activity induces hyperphosphorylation and altered compartmentalization of tau in transgenic mice. J Biol Chem 276: 38193-38200, 2001.

38. Zhu D, Kosik KS, Meigs TE, Yanamadala V and Denker BM: Galpha12 directly interacts with PP2A: evidence for Galpha12stimulated PP2A phosphatase activity and dephosphorylation of microtubule-associated protein, tau. J Biol Chem 279: 54983-54986, 2004.

39. Christmann M, Pick M, Lage H, Schadendorf D and Kaina B: Acquired resistance of melanoma cells to the antineoplastic agent fotemustine is caused by reactivation of the DNA repair gene MGMT. Int J Cancer 92: 123-129, 2001.

40. Li HH, Cai X, Shouse GP, Piluso LG and Liu X: A specific PP2A regulatory subunit, B56gamma, mediates DNA damageinduced dephosphorylation of p53 at Thr55. EMBO J 26: 402-411, 2007.

41. Blough MD, Zlatescu MC and Cairncross JG: $\mathrm{O}^{6}$-methylguanineDNA methyltransferase regulation by $\mathrm{p} 53$ in astrocytic cells. Cancer Res 67: 580-584, 2007.
42. Ruvolo PP: Intracellular signal transduction pathways activated by ceramides and its metabolites. Pharmacol Res 47: 383-392, 2003.

43. Hirose Y, Katayama M, Mirzoeva OK, Berger MS and Pieper RO: Akt activation suppresses Chk2-mediated, methylating agentinduced G2 arrest and protects from temozolomide-induced mitotic catastrophe and cellular senescence. Cancer Res 65: 4861-4869, 2005 .

44. Cha TL, Zhou BP, Xia W, et al: Akt-mediated phosphorylation of EZH2 suppresses methylation of lysine 27 in histone H3. Science 310: 306-310, 2005 .

45. Sunters A, Grimaldi KA, Souhami RL and Hartley JA: Gene and human tumour cell line specific differences in nitrogen mustard induced DNA alkylation and interstrand crosslinking frequencies. Nucleic Acids Res 26: 5617-5623, 1998.

46. Bellmann K, Martel J, Poirier DJ, Labrie MM and Landry J: Downregulation of the PI3K/Akt survival pathway in cells with deregulated expression of c-Myc. Apoptosis 11: 1311-1319, 2006.

47. Yeh E, Cunningham M, Arnold $\mathrm{H}$, et al: A signalling pathway controlling c-Myc degradation that impacts oncogenic transformation of human cells. Nat Cell Biol 6: 308-318, 2004

48. Biroccio A, Benassi B, Fiorentino F and Zupi G: Glutathione depletion induced by c-Myc downregulation triggers apoptosis on treatment with alkylating agents. Neoplasia 6: 195-206, 2004. 